\title{
O “PACTO PELA EDUCACÃO” E O MISTÉRIO DO “TODOS”: ESTADO SOCIAL E CONTRARREFORMA BURGUESA NO BRASIL
}

\author{
Álcio Crisóstomo Magalhães* \\ Universidade Estadual de Goiás (UEG) - Campus Goiânia/ESEFFEGO, Goiânia - GO, Brasil \\ José Adelson da Cruz** \\ Universidade Federal de Goiás (UFG), Goiânia - G0, Brasil
}

RESUMO: Apreender o modo como o Brasil reorganiza seu sistema de ensino ao longo da Revolução Passiva ou de redefinição dos limites de seu Estado social é compreender que a atual Contrarreforma, muito mais que produto, é processo. A análise do modo como se autoriza e legitima um partido de classe burguesa - na acepção gramsciana -, o movimento "Todos Pela Educação", impõe o entendimento da tensão entre público e privado no campo da educação. É o que se conclui ao se cotejar as diretrizes institucionais da entidade às metas e estratégias do "Plano Nacional de Educação 2014/2024" e, em especial, aos pilares do "Pacto Pela Educação" em Goiás, como rearranjo local do repertório vocabular do grande capital internacional. Demonstrar esse transformismo é o propósito desta reflexão, que se configura como um recorte da pesquisa que procura apreender a relação entre as reformas educacionais pós anos 1990 e a organização do trabalho pedagógico em Goiás.

Palavras-chave: Pacto Pela Educação. Todos Pela Educação. Trabalho docente. Contrarreforma. Organizações Sociais.

THE "EDUCATIONAL PACT" AND THE MYSTERY "ALL": SOCIAL STATE AND COUNTERREFORM IN BOURGEOIS IN BRAZIL

ABSTRACT: Learning the way Brazil reorganizes its education system along the Passive Revolution or reset the boundaries of their social state is to understand that thecurrent Counter-Reformation much more than product is the process. The analysis of how it authorizes and legitimizes a bourgeois class party - in the Gramscian sense - the "Education For All Movement"

\footnotetext{
"Doutor em Educação pela Faculdade de Educação da Universidade Federal de Goiás (FE/UFG). Docente da Universidade Estadual de Goiás, Campus ESEFFEGO/Goiânia (UEG/ESEFFEGO). Professor pesquisador do Laboratório de Pesquisa em Lazer, Esporte e Estudos do Corpo (LAPELEC). E-mail:<alciocri@gmail.com>. " Doutor em Educação pela Faculdade de Educação da Universidade Estadual de Campinas (UNICAMP). Professor Associado do Programa de Pós-graduação da Faculdade de Educação da Universidade Federal de Goiás. E-mail:<jadelsoncruz@uol.com.br >.
} 
requires understanding the tension between public and private in the field of education. This is we conclude when comparing the institutional guidelines of the Entity to the Goals and Strategies of the National Education Plan 2014/2024 and, in particular, the Pillars of the "Pact for Education" in Goiás, as the local rearrangement of the vocabulary repertoire of the big international capital. Demonstrating this transformism is the purpose of this reflection, which is configured as a research cut that seeks to understand the relationship between educational reforms after 1990 and the organization of pedagogical work in Goiás

Keywords: Pact for Education. All for Education. Teaching work. CounterReformation. Social Organizations.

\section{INTRODUC̣ÃO}

Ratificando a tese de uma sociedade que desde a emergência do Estado Novo vem assentando-se em um projeto de Revolução pelo alto ou passiva, gramscianamente falando, a Constituição de 1988 não só redefiniu as bases do Estado social brasileiro como também sugeriu o florescimento do grande pacto liberal nacional. Não é por acaso que a década de 1990 e o início dos anos 2010 correspondem a um ciclo histórico de fortuna da ideologia do consenso. Esse pacto conseguiu desmobilizar, durante décadas, os movimentos sociais e as organizações políticas. Mesmo que os tenha integrado ao aparato de Estado, em nome da aparente realização e conquista das bandeiras históricas dos mesmos, se efetivou como regressão do político. Esse recorte não é outro senão o que delimita a Contrarreforma, a dinâmica de restauração da ordem burguesa no país. Um movimento cíclico que, nessa quadra histórica, notabiliza-se pelo enxugamento do público, flexibilização das conquistas trabalhistas e precarização dos direitos sociais: "existe um relativo consenso de que é necessário privatizar - dada a crise fiscal - e conveniente privatizar, dada a maior eficiência e a menor subordinação a fatores políticos das empresas privatizadas" (PEREIRA, 1998, p. 66).

O conceito de Contrarreforma nas políticas educacionais, tese central deste artigo, é apanhado em Gramsci (2002, p. 143), que caracteriza a Contrarreforma como uma pura e simples "restauração" e "conservação" da ordem social e política, diferente da Revolução Passiva, entendida como "revolução-restauração" ou modernização. Ou seja, a Revolução Passiva é o reformismo conservador, "dirigido pelo alto", capturando e cooptando as demandas populares. Porém, segundo Gramsci (2002), estas demandas são "selecionadas" e "conciliadas" com os interesses do grupo hegemônico, tornando-as compatíveis, em última instância, com as necessidades de reprodução 
do capital. Em outros termos, a Revolução Passiva se efetiva quando as classes dominantes, pressionadas pelos de baixo, acolhem para continuar dominando e até mesmo para obter o consenso e o consentimento passivo por parte dos subalternos - "uma certa parte das exigências que vinham de baixo"1.

$\mathrm{Na}$ história brasileira, a passagem à ordem burguesa se caracteriza como um caso de "revolução sem revolução", deslanchada pelo Estado corporativo da década de 1930. A lógica do "conservarmudando", segundo Vianna (1997, p. 43), é a marca da "revolução passiva à brasileira". Isso porque a emergente sociedade de massas, com a urbanização e a industrialização, configurou a questão social - dissociada do político -como "fermento revolucionário" da nossa Revolução Passiva: a incorporação das massas urbanas ao mundo do direito; a modernização econômica como estratégia de criar novas oportunidades de vida às camadas subalternas; e a conservação das relações de dependência pessoal e concentração da terra. Por sua vez, o "reformismo social", com a formalização das práticas e instituições do Estado, operou a "estatização da vida social".

Significa dizer que toda dinâmica social, suas instituições, seu sistema de orientação hegemônico, sua produção legislativa e jurisdicional seriam projeções da esfera estatal, constituindo uma complexa malha democrático-burocrática que não poderia existir sem o protagonismo dos intelectuais. (VIANNA, 1997, p. 13)

Podemos supor, assim, que a diferença essencial entre uma Revolução Passiva e uma Contrarreforma resida no fato de que, enquanto na Revolução Passiva certamente existem "restaurações", mas que acolheram as reivindicações que vinham de baixo, na Contrarreforma o preponderante não é o momento do novo, mas precisamente o do velho, "conservação e restauração". Trata-se de uma diferença talvez sutil, mas que tem um significado importante para pensarmos o movimento "Todos Pela Educação" e as atuais políticas educacionais. Outra importante observação de Gramsci refere-se ao fato de que a Contrarreforma não se define como tal, como um movimento restaurador, reacionário, mas busca apresentarse como uma "reforma progressista".

O "conservar-mudando" - marca da Revolução Passiva à brasileira - é tributário das elites políticas que buscam criar condições para que o "reformismo social" venha confirmar e atualizar seu domínio. É nessa cultura política que se assentaram as bases para o aprisionamento ou "transformismo" dos movimentos sociais em organizações de interesses privados, bem como para a ressignificação do conceito de Sociedade Civil e que, por conseguinte, suscitaram 
reflexões teóricas e políticas de ponta a ponta acerca da virtualidade da Sociedade Civil. A esquerda viu nesse deslocamento a possibilidade de radicalização da democracia direta. Por sua vez, a direita passou a concebê-la como a substituta virtuosa do Estado. Assim, a Sociedade Civil assumiu no discurso das forças reacionárias do bloco histórico nacional o status de vacina contra o Estado ineficaz e corrupto. Esse argumento ganhou centralidade no âmbito da ideologia neoliberal de Estado mínimo, que assegurou a privatização dos bens públicos através de acordos com Organizações Sociais. Nesse mesmo movimento, as lutas sociais ganharam outros sentidos e novos significados. No campo empresarial, emerge a ideia de empresa adjetivada de filantropia, responsabilidade social ou empresa cidadã, bem como se converte o direito social à escola, por exemplo, em mercadoria, e as políticas aos princípios do "menor custo".

Conforme Cruz (2005) tornou-se pensamento hegemônico identificar a sociedade civil como um conjunto de atores empíricos, unificados pelos alcances normativos da "solidariedade", portadores de interesses gerais e capazes de formatar novos espaços públicos. Esse consenso projetou uma complexa relação entre lei e política, tribunais e representação popular, república e democracia, indicadora da intenção de se despolitizar os conflitos em favor da negociação entre grupos de interesses. Entre nós, a sociedade civil se consolidou como sinônimo de Terceiro Setor, o conluio entre organizações filantrópicas, comunitárias e ONGs. Esse deslocamento resultou em uma concepção de sociedade civil acrítica e polêmica, deixando de ser um instrumento de analise-teórico e se convertendo em estratégias ideológico-práticas de privatização do público.

Nesse novo contexto de repactuação, falar em classe ou, o que é pior, em conflito de classe, passou a soar quase como heresia. Para um número considerável de estudiosos de praticamente todas as áreas das ciências sociais e humanas, o Brasil dos anos $1990 \mathrm{em}$ diante teria instituído a conciliação entre trabalho e capital como o novo motor da história. O país teria finalmente conseguido promover o diálogo entre Estado, empresários, operários e uma série de entidades sem fins lucrativos (OLIVEIRA, 2007). Tal procedimento tende a ocultar os limites e as possibilidades de "republicanizar" a política e o Estado.

Desde a "transição negociada", em meados da década de 1980, com o Pacto de Reconciliação Nacional, esta concepção prático-teórica ganhou forma e expressão política e acadêmica no Brasil. Essa maneira de pensar a relação entre sociedade e Estado é central nos programas de governo e nas políticas públicas sociais. Focada na ideia de inclusão, acabou por transformar a luta contra 
a miséria e a desigualdade social em um problema de gestão das políticas públicas. Assim, a funcionalização ou a instrumentalização da pobreza transformou a miséria em uma questão administrativa e de controle social. Isso revela também como o mercado acabou dominando a política educacional e até os critérios que orientam a ação pedagógica. Sistematicamente, esta lógica é aplicada para planejar políticas educacionais, com prioridade no custo-benefício, e não na qualidade social da educação. Assim, é possível ser um bom gestor sem entender nada de educação, tornar-se diretor eficaz de escolas sem conhecer as sutilezas e argúcias teleológicas que se escondem na organização do trabalho pedagógico, ou mesmo ser um eficiente chefe do executivo federal, estadual, municipal ou de suas respectivas secretarias sem ter nenhum zelo com o bem público.

O ciclo de Contrarreforma é exatamente o pulsar desses novos acordes. Um exemplo é a criação de condições materiais necessárias para a aprovação da Lei n. ${ }^{\circ} 9.790$ de 1999 , que regulamenta a expansão do chamado terceiro setor, especialmente por meio das Organizações da Sociedade Civil de Interesse Público (OSCIPs), conhecidas como Organizações Não Governamentais (ONGs), ou simplesmente como Organizações Sociais (OS). Tal lei constituiu a materialidade da Contrarreforma, pois secundariza os direitos sociais. A justificativa para o estabelecimento de parcerias entre o público e o privado para tratar da questão social é do próprio operador da reforma do Estado: "Os investimentos na infraestrutura e nos serviços públicos não são, a rigor, uma atividade exclusiva do Estado, na medida em que podem ser objeto de concessão" (PEREIRA, 1998, p. 65). Portanto, uma nova institucionalidade reelaborada pelos intelectuais orgânicos a serviço da reprodução, em nível local, das mistificações do grande capital: "na verdade são entidades públicas não estatais, ou seja, usando-se os outros nomes que são designados, são entidades do terceiro setor, são entidades sem fins lucrativos, são organizações não governamentais, organizações voluntárias” (PEREIRA, 1998, p. 67).

Para Oliveira (2007), se trata não mais do que uma tese que se baseia na dispersão da sociedade civil em microcentros de organização do social, ou seja, a defesa de “uma 'onguização' da política social que concorre com o Estado e com os partidos desde a formulação de políticas locais e focalizadas até a distribuição de alimentos" (OLIVEIRA, 2007, p. 41). As ONGs nascidas como porta-vozes da nova complexidade da sociedade brasileira, em confronto com a ditadura civil-militar, se transformaram em organizações supletivas das insuficiências do aparelho estatal e estão no interior de um complexo processo de disputa de sentidos do que é o "social" e o 
"político". Isso se ampliou cada vez mais com a entrada em cena das organizações de "ética empresarial", transformando a educação e a cultura em territórios não conflitivos.

É na esteira da hegemonia burguesa, direção moral e intelectual, criada a reboque da atualização do projeto de Revolução Passiva à brasileira, na qual se efetivou a modernização, negando os princípios do moderno e da Res pública, que muitos movimentos sociais legítimos passam a se confundir com Organizações Sociais e, desse modo, a se deslocar dos protestos e lutas sociais para as disputas no campo das políticas públicas e dos fundos públicos.

Aqui, muito mais que exercício de boa ou má vontade, temse nitidamente a reprodução dos princípios estruturais do sistema de produção de mercadorias, que, a partir dos anos finais da década de 1980, adotou como uma das estratégias de expansão/conservação/ restauração a transformação do mundo público em espaço de defesa de interesse de grupos privados. Muito em função da variação da dinâmica de reprodução do sistema de acumulação capitalista do eixo Inglaterra/ EUA dos 1980, o Brasil começa a desenvolver no final do século XX as condições para a reconfiguração dos limites de seu Estado social.

A partir da segunda metade da década de 1990, por meio da combinação e continuidade de FHC, Lula e Dilma, o país produziu o consenso necessário para a regulamentação do Pacto Constitucional de 1988. Assim sendo, criou a atmosfera que possibilitou, por exemplo, a aprovação da LDB 9.394/96, a Lei de Diretrizes e Bases da Educação Nacional, simultaneamente expressão do conflito de classes e guarida dos empresários da educação. Além disso, também criou as condições de fato e de direito para o surgimento do movimento "Todos Pela Educação", sugerindo uma ideia de consenso a partir do próprio nome/ slogan e atualizando as bases do projeto nacional de Revolução Passiva. A organização "Todos Pela Educação", criada em 2005 (portanto, exatamente no fechamento da primeira década do ciclo de transição negociada), passou a articular as elites econômicas nacionais em torno da criação de uma grande comunidade em defesa da escolarização pública.

\section{O MOVIMENTO TODOS PELA EDUCAÇÃO E A CONTRARREFORMA NAS POLÍTICAS EDUCACIONAIS}

O movimento "Todos Pela Educação" passou a reivindicar para si o monopólio de fala no debate nacional acerca de todas as questões referentes à educação: qualidade, gestão, formação de professores, organização do trabalho pedagógico, investimento e 
avaliação. Nesse caso, entenda-se "reivindicar para si" como sinônimo do esforço dos grupos empresariais do setor de telecomunicações e publicidade, do mercado financeiro, das diversas fundações e instituições ligadas às grandes corporações em assumir a prioridade na definição das políticas para a educação. Portanto, o conluio dos parceiros locais do grande capital, grupos Roberto Marinho, Victor Civita, Gerdau, Bancos Itaú/Unibanco, Bradesco e Santander, entre outros, com o propósito de balizar todo o sistema público de ensino do país, orientando desde a destinação dos recursos, passando pela gestão das escolas, até a organização curricular. É o próprio "Todos" que afirma esse propósito.

Em parceria com o Banco Interamericano de Desenvolvimento (BID), o Instituto Natura, o Itaú, o BBA, a Samsung e a Fundação Telefônica Vivo, o TPE desenvolve o projeto Métodos Inovadores de Ensino. A iniciativa tem como objetivo contribuir para a garantia de uma Educação de qualidade para todos e para o uso eficiente dos recursos públicos da Educação por meio da identificação e da construção de instrumentos que permitam aos professores, gestores escolares e gestores públicos: 1) diagnosticar as possibilidades de adoção de tecnologias na Educação - escolas e redes de ensino; 2) avaliar a pertinência das soluções disponíveis; 3) avaliar os resultados alcançados com a adoção das tecnologias selecionadas. (TODOS PELA EDUCAÇÃO, [2016?], [s.p.])

Nesse sentido, por meio do sequestro de expressões universais e, por assim dizer, aparentemente acima de qualquer interesse de classe, tais como "educação de qualidade", "educação para todos", "uso eficiente dos recursos públicos", "gestão", "tecnologias", "soluções", nota-se o nítido propósito de intensificar a inclusão da educação pública na agenda mundial de reforma fiscal do Estado. Assim sendo, novamente a reedição de uma velha fórmula que faz fortuna no processo de modernização brasileira. A ação ideológica das organizações culturais a bem da ressignificação partidária de um léxico universal.

A organização "Todos Pela Educação" requenta essa fórmula, mas, entretanto, renovando-a com a ideia de premência do tempo e de unidade em torno de uma suposta causa maior, algo que se sobreporia a qualquer tipo de diferença, conforme se pode perceber nos lemas/ títulos de seus dois primeiros congressos: "Educação: agenda de todos, prioridade nacional" e "Educação: uma agenda urgente".

Insinuando-se apartidário, ou seja, isento de qualquer motivação corporativista, cria fóruns em aberta concorrência com a Conferência Nacional de Educação, com o propósito de formar uma "opinião pública" avessa ao princípio do Estado como ente responsável por gerir os bens públicos, especialmente aqueles que, a partir da reconfiguração do Estado social brasileiro, passaram 
a ter dotação orçamentária própria e resguardada legalmente. Contraditoriamente, trata-se do esforço de criação de um espírito de recusa ao que já fora dado como elemento da experiência moderna.

A estratégia de ativar a pauta da grande mídia e de promover eventos temáticos para discutir questões como "justiça pela qualidade da educação", "regime de colaboração", "equidade", "expectativas de aprendizagem", "formação inicial do professor", "avaliações externas" e "gestão educacional" refletem o modus operandi do "Todos Pela Educação", qual seja, criar tribunais de julgamento e condenação do Estado, o que corresponde a deslegitimá-lo como operador de recursos e, por extensão, salvaguardar a prioridade da classe burguesa no gerenciamento do bem público.

O consenso expresso em um documento como o "Plano Nacional de Educação 2014/2024" e as propostas do movimento "Todos Pela Educação" indicam muito claramente quão efetiva tem sido a ação de classe dos empresários da educação, representantes diretos da elite econômica brasileira. Tanto é verdade que, ao longo do período de maior popularidade do Governo Dilma Rousseff, o empresário Jorge Gerdau, Presidente do Conselho de Governança do "Todos", foi Coordenador da Câmara de Políticas de Gestão, Desempenho e Competitividade da Presidência da República.

Contudo, considerando que o que está de fato em jogo na Contrarreforma do Estado brasileiro é a intensificação dos mecanismos de reprodução do grande capital, o movimento "Todos Pela Educação" vem dando cabo a este projeto. Muito vorazmente, por meio da estratégia de convencimento da opinião pública, vem impondo como universal seu particular de educação. Leia-se como prova o fato de que o Decreto 6.094, publicado em 2007 (portanto, no auge do governo Lula da Silva), quer e produz no "Plano de Metas Compromisso Todos Pela Educação" e em diversos artigos quase que literalmente os princípios da entidade.

Art. $1^{\circ} \mathrm{O}$ Plano de Metas Compromisso Todos Pela Educação (Compromisso) é a conjugação dos esforços [...] em regime de colaboração, [...] em proveito da melhoria da qualidade da educação básica.

$[\cdots]$

II - alfabetizar as crianças até, no máximo, os oito anos de idade, aferindo os resultados por exame periódico especifico;

$[\cdots]$

XIV - valorizar o mérito do trabalhador da educação [...].

$[\cdots]$ 
XVIII - fixar regras claras, considerados mérito e desempenho, para nomeação e exoneração de diretor de escola;

$[\cdots]$

XXVIII - organizar um comitê local do Compromisso, com representantes das associações de empresários, trabalhadores, sociedade civil, Ministério Público, Conselho Tutelar e dirigentes do sistema educacional público, encarregado da mobilização da sociedade e do acompanhamento das metas de evolução do IDEB.

$[\cdots]$

Art. $3^{\circ}$ A qualidade da educação básica será aferida, objetivamente, com base no IDEB, calculado e divulgado periodicamente pelo INEP. Parágrafo único. O IDEB será o indicador objetivo para a verificação do cumprimento de metas fixadas no termo de adesão ao Compromisso. (BRASIL, 2007, [s.p.], grifo nosso)

Princípios esses que voltam a ser ratificados no "Plano Nacional de Educação 2014/2024”. A Estratégia 7.11, por exemplo, prevê "Melhorar o desempenho dos alunos da educação básica nas avaliações da aprendizagem no Programa Internacional de Avaliação de Estudantes (PISA), tomado como instrumento externo de referência [...]” (BRASIL, 2014). Na mesma direção aponta a Estratégia 7.36, quando institui que sejam estabelecidas "políticas de estímulo às escolas que melhorarem o desempenho no Ideb [Índice de Desenvolvimento da Educação Básica], de modo a valorizar o mérito do corpo docente, da direção e da comunidade escolar" (BRASIL, 2014).

O Plano Decenal 2014/2024, além de reproduziros termos-chave do "Todos", transforma em meta de Estado a transferência de recursos públicos para grupos privados e intensifica o processo de conversão do aparelho estatal em ente de promoção da divisão social do trabalho via Rede Federal de Ensino. As Metas 11 e 12, que tratam, respectivamente, da expansão do financiamento público do ensino profissional, via PRONATEC, e do custeio de mensalidades em faculdades particulares para estudantes de menor poder aquisitivo, via FIES, expressam bem as bandeiras recorrentes de qualquer cartilha das empresas e fundações vinculadas ao movimento "Todos Pela Educação".

A Meta 11:

11.1) expandir as matrículas de educação profissional técnica de nível médio na Rede Federal de Educação Profissional, Científica e Tecnológica, levando em consideração a responsabilidade dos Institutos na ordenação territorial, sua vinculação com arranjos produtivos, sociais e culturais locais e regionais, bem como a interiorização da educação profissional[.] (BRASIL, 2014, [s.p.])

\section{A Meta 12:}

12.6) expandir o financiamento estudantil por meio do Fundo de Financiamento 
Estudantil - FIES, de que trata a Lei n. ${ }^{\circ}$ 10.260, de 12 de julho de 2001, com a constituição de fundo garantidor do financiamento, de forma a dispensar progressivamente a exigência de fiador[.] (BRASIL, 2014, [s.p.])

Evidentemente que, nesse caso, não se tem nenhuma coincidência. O consenso expresso em um documento como o "Plano Nacional de Educação 2014/2024", aprovado no governo Dilma Rousseff, indica muito claramente quão efetiva tem sido a ação de classe dos empresários da educação, representantes diretos da elite econômica brasileira. Nesse mesmo governo, a Secretaria de Educação Básica do MEC foi comandada por Cesar Callegari, enquanto o Conselho Nacional de Educação teve como um de seus membros Mozart Neves Ramos. Tal qual Gerdau, ambos são membros ativos do Conselho de Governança da organização "Todos Pela Educação". Callegari, além da responsabilidade pela construção do chamado "Pacto Nacional pela Alfabetização na Idade Certa", foi membro do Conselho de Acompanhamento e Controle Social do FUNDEB. Já o senhor Ramos não é outro senão o ex-presidente do movimento "Todos Pela Educação" e articulista de educação do Instituto Milênio, organização social composta por uma rede de economistas, advogados, sociólogos, cientistas políticos, jornalistas e educadores que, seguindo a mesma racionalidade do "Todos", mas em uma perspectiva macroestrutural, vem atuando efetivamente na produção do consenso necessário à Contrarreforma das bases do Estado social brasileiro.

Nesse mesmo contexto, mais precisamente em 2011, a organização criou, em parceria com o Banco Interamericano de Desenvolvimento - BID e com o apoio da União Europeia, a Rede Latino-Americana de Organizações da Sociedade Civil pela Educação - REDUCA. Um grande partido da classe burguesa, formado pela Asociación Empresarios por la Educación (Peru), Grupo Faro (Equador), Educa - Acción Empresarial por la Educación (República Dominicana), Educación 2020 (Chile), Empresarios por la Educación (Guatemala), Foro Educativo Nicaragüense "Eduquemos" (Nicarágua), Fundación Empresarial para el Desarollo Educativo (El Salvador), Fundación Empresarios por la Educación (Colômbia), Fundación para la Educación Ernesto Maduro Andreu (Honduras), Juntospor la Educación (Paraguai), Mexicanos Primero (México), Proyecto Educar 2050 (Argentina), Todos Pela Educação (Brasil) e Unidos por la Educación (Panamá), constitui um conluio de entidades privadas que adota como modus operandi apresentar-se como expressão de um consenso, o que lhes asseguraria o direito de definir as políticas de governo, ou seja, atrelá-las ao processo de produção de mercadorias. 
Nesse caso, novamente há o esforço de reelaboração, a partir das componentes político-sociais e econômicas locais, ao receituário made in U.S.A. A organização "Todos Pela Educação" tem como referência de ação a lógica gerencial dos grandes grupos privados norte-americanos, experimentada, desde a década de 1990, pelo governo George W. Bush. A avaliação da reforma No Child Left Behind (NCLB - "Nenhuma Criança Para Trás"), Lei que atende aos ditames da ala reacionária do Congresso Nacional, dos grandes empresários defensores do livre mercado e das grandes fundações, atrelou a política educacional do país à racionalidade fabril. Curiosamente, a mea-culpa de uma professora da Universidade de Nova York, a Conselheira e Secretária-Adjunta no Departamento de Educação dos Estados Unidos, uma das principais intelectuais orgânicas do projeto que ampliou a privatização e a submissão do sistema de ensino do país a testagens padronizadas, à responsabilização punitiva e à multiplicação de escolas autônomas, assinala:

Os novos reformadores corporativos demonstram sua precária compreensão da educação, construindo falsas analogias entre a educação e o mundo empresarial. Eles pensam que podem consertar a educação aplicando princípios de negócios, organização, administração, lei e marketing [...] para incentivar a força de trabalho - diretores, professores e estudantes - com recompensas e sanções apropriadas. Como esses reformadores, eu escrevi e falei com convicção nos anos 1990 e no começo dos 2000 [...]. (RAVITCH, 2011, p. 27)

É a própria Diane Ravitch (2011), uma das mentoras da transformação da escola norte-americana em campo de experimentação da qualidade total empresarial - ideologia do mérito -, que, ao final da primeira década da reforma do sistema de ensino dos Estados Unidos, passa a engrossar o coro dos que atestam que a racionalidade da educação, baseada em obtenção de índices, além de não significar qualidade em uma perspectiva substantiva, colocou em risco o princípio democrático, grande pilar da ideologia do Estado Democrático de Direito norte-americano. Pelo menos é essa a constatação da própria Ravitch (2011) em Vida e Morte do Grande Sistema Escolar Americano: como os testes padronizados e o modelo de mercado ameaçam a educação.

A estratégia de ocupação de escolas por alunos, pais e professores como luta pela consolidação dos direitos públicos e sociais se tornou símbolo de resistência ao desmanche da escola pública no Brasil. Ocorreram ocupações em Goiás, contra a transferência do controle das escolas para Organizações Sociais e Polícia Militar; no Rio de Janeiro, contra as más condições das escolas, com um corte de recursos enorme; em São Paulo, contra a reorganização da Rede e contra a falta de merenda escolar; e também houve ocupações no 
Ceará e no Pará. Portanto, é um processo que está se espalhando e enfrentando um forte aparato policial no momento das desocupações. Em Goiás, as universidades e sindicatos dos profissionais da educação frequentemente se manifestam contra a privatização e a submissão do sistema de ensino à lógica mercantil.

Para que se tenha uma ideia da efetividade do movimento, só em 2014, oito Estados brasileiros, em maior ou menor escala, e, ainda, muitas de suas capitais e cidades metropolitanas, condicionavam suas reformas educacionais às diretrizes da REDUCA. Dentre eles, o Estado de Goiás. Não por obra do acaso, é claro, exatamente no mesmo ano de criação da Organização, o governo goiano instituiu sua Contrarreforma com o "Pacto Pela Educação", o arranjo local da Rede Latino-Americana.

\section{OSNEGÓCIOSDO“PACTO”:AÇÃODEPARTIDOEAJUSTEFISCALNACONTRARREFORMA EDUCACIONAL GOIANA}

Em dezembro de 2011, a Assembleia Legislativa de Goiás, acatando literalmente o projeto da Secretaria Estadual de Educação de Goiás, aprovou a Lei n. ${ }^{\circ} 17.402$, de 6 de setembro de 2011, que instituiu o chamado "Pacto Pela Educação", uma espécie de radicalização autoritária dos princípios do REDUCA. Reproduzindo a ideia de urgência e de coletividade em comunhão, o sistema de ensino goiano foi reduzido a lócus de experimentação da chamada educação de resultados.

A Contrarreforma atrelou o funcionamento da escola pública de Goiás à mesma racionalidade que vem sendo fomentada mundialmente pelos grandes financiadores do capitalismo e que, no Brasil, tem a organização "Todos Pela Educação" como um de seus intelectuais orgânicos. Isso significa dizer que o repertório argumentativo dos consultores contratados para implantar a reestruturação em Goiás não vai além da reprodução do léxico do "Todos". A tese da terra arrasada, da urgência do novo, por exemplo, lugar comum dos diversos fóruns e meios de comunicação da organização, é apresentada como a principal justificativa da sra. Wanessa Ferreira para a implantação do "Pacto" goiano.

O Pacto Pela Educação teve como motivador um cenário de crise da educação pública goiana, após anos de níveis de aprendizado e taxas de evasão piores que a média nacional. [...] O ensino médio de todo o País precisa passar por uma grande renovação, e o primeiro passo para isso é definir um novo currículo mais flexível. (FERREIRA, 2015, [s.p.]) 
Para que não se tenha dúvida da natureza mercantil do projeto, é fundamental que se leve em conta que a sra. Ferreira trata-se de uma consultora da norte-americana Bain \& Company, contratada pela Secretaria Estadual de Educação de Goiás com o propósito de gerenciar a Contrarreforma. É a própria companhia que eufemisticamente apresenta seus propósitos econômicos:

A Bain \& Company Brasil abriu seu escritório em São Paulo em 1997, e em 2011 chegou ao Rio de Janeiro. Juntamente com nossos escritórios de Buenos Aires e Santiago, atendemos clientes locais e multinacionais orientados à mudança em diversos setores de negócios por toda a América do Sul. O escritório de São Paulo foi fundado em 1997, por uma equipe de empreendedores brasileiros e italianos da Bain, que enxergaram uma oportunidade de elevar os padrões de consultorias estratégicas no Brasil e na América Latina. (BAIN \& COMPANY BRASIL, [2016?], [s.p.])

Em outros termos, corresponde a uma corporação multinacional especializada na conversão de recursos públicos em dividendos para grupos privados. Isso fica nítido quando se percebe a consonância entre os valores corporativos de ambas (patroa e empregada) e a grande tese do manual da economia da educação, desenvolvido ainda na década de 1960, na Escola de Chicago:

Com o foco no capital humano, há seleção, desenvolvimento e retenção de lideranças e professores de alto desempenho. Além disso, é criada uma cultura inspiradora de alta expectativa com a definição de um currículo rigoroso e a ampliação da carga horária de aula, com personalização do ensino por meio de grupos de monitoria. (FERREIRA, 2015, [s.p.], grifo nosso)

Tendo como princípio educativo o fetiche dos testes, a redução da avaliação a instrumental de obtenção de índices, a exposição pública de comunidades escolares, a premiação e a punição de professores e alunos, a quebra da perspectiva de carreira docente e, especialmente, o controle do controle, a Contrarreforma goiana vem revelando o caráter reacionário do movimento. Isso equivale a dizer que o "Pacto Pela Educação" é a evidência dos limites do projeto internacional de reforma fiscal que tenta se ocultar na parcialidade da ideologia do consenso e na articulação dos grandes grupos econômicos que se revezam em veículos de comunicação e nos diversos fóruns temáticos criados com o propósito de legitimá-lo.

$\mathrm{Na}$ fala do líder religioso e empresário do setor de comunicações que vem se constituindo em uma das principais expressões do protestantismo religioso em Goiás, a ideia de autoridade, vontade coletiva e divisão dos docentes em bons e maus se evidencia: 
As ideias do governo não surgiram de repente, nem vieram de mentes incautas. As mudanças são propostas reunidas em uma série de debates em todo o país, com especialistas e também com os mais interessados - estudantes e pais. A funcionalidade dessa ideia está na política de bonificação e premiação por mérito. (AUGUSTO, 2012, [s.p.])

No evento promovido pelo principal grupo de comunicação do Estado de Goiás, a análise aparentemente isenta, visando ao mesmo tempo deslegitimar e justificar a reação dos professores, enfatiza: "mudanças, de forma geral, geram resistências, e não foi diferente para as mudanças estruturais (e culturais) que estavam por trás dos 5 pilares e 25 iniciativas do Pacto" (LIMA, 2015, [s.p.]).

Em setembro de 2015, o Grupo Jaime Câmara promoveu a quinta edição de seu Fórum "Agenda Goiás", enfatizando muito explicitamente a necessidade da intensificação dos princípios norteadoras da Contrarreforma goiana. A matéria jornalística que apresentou a tese do principal palestrante do Evento, o Senador da República que se apresenta nacionalmente como uma espécie de Dom Quixote da educação brasileira, permite muito claramente essa compreensão:

Ao participar hoje (03/09), em Catalão, da 5. ${ }^{a}$ edição do fórum Agenda Goiás, o senador Cristovam Buarque (PDT-DF), principal palestrante do seminário, afirmou que Goiás não pode perder a oportunidade de testar o sistema de Organizações Sociais (OS) na Educação. "É uma experiência que merece ser testada", disse Cristovam, ex-ministro da Educação e defensor do modelo público e gratuito. Segundo o senador, é preciso acabar com o estigma de que "tudo que é público é sinônimo de Estado e tudo que é privado é sinônimo de lucro". Para ele, é importante que novas alternativas sejam discutidas na Educação e uma delas é o sistema de gestão por meio de Organizações Sociais. (LIMA, 2015, [s.p.], grifo nosso)

$\mathrm{Na}$ fala de Thiago Peixoto, o economista encarregado de administrar a Secretaria Estadual de Educação à época da Contrarreforma goiana, retoma-se novamente as ideias de novidade, de importação, de comparação e de competição como forma de validação do arranjo local: "Aqui hoje nós vamos confrontar o modelo tradicional com dois modelos novos, a federalização e as charters schools, apostando que daqui sairá algo novo. Conseguimos o primeiro lugar, mas queremos avançar" (PEIXOTO, 2015, [s.p.]).

No discurso do Diretor Superintendente da entidade patronal SEBRAE/GO, Igor Montenegro, há a reprodução da tese da vinculação da educação aos princípios da atual fachada do sistema de acumulação do capital, uma espécie de senha, mantra, fixação dos reformadores empresariais da educação: "Educação e empreendedorismo caminham juntos e podem ajudar a salvar o País" (MONTENEGRO, 2015, [s.p.]). 
Portanto, quando se passa em revista o modo como os grandes grupos dirigentes do Estado apresentam os cinco pilares da reforma goiana, quais sejam, "valorizar e fortalecer o profissional da educação", "realizar profunda reforma na gestão e na infraestrutura da rede estadual de ensino", "adotar práticas de ensino de alto impacto na aprendizagem", "reduzir significativamente a desigualdade educacional", "estruturar o sistema de reconhecimento e remuneração por mérito" e "ser referência nacional em educação", o que se evidencia de fato é a reedição do movimento do grupo econômico que desde o início dos anos 1990 vem criando as condições para que o Estado brasileiro assuma a centralidade no financiamento do grande capital internacional.

A ação de classe da organização "Todos Pela Educação" em Goiás, com o "Pacto Pela Educação" desde seu movimento inicial em 2011, é de convencimento da opinião pública e criação das condições para a segunda fase em 2015, com a efetivação da privatização do patrimônio público, por meio da transferência do controle das escolas para grupos privados respaldados pelos dispositivos da Lei n. ${ }^{\circ} 9.637 / 1998$, que cria as ditas Organizações Sociais.

O modo como se apresenta o grande eixo estruturante da Contrarreforma goiana, "Bônus de Estímulo à Regência”, por sugerir uma ideia de valorização dos bons professores, induziu grande parte da opinião pública do Estado de Goiás a considerar legítimo o dispositivo da vinculação dos ganhos docentes à frequência diária e à entrega de planos de aula. $\mathrm{Na}$ esteira dessa engrenagem que os reformadores empresariais apelidaram de meritocracia, passou a deslizar todo o pacote de medidas necessárias à efetivação do gradual e contínuo processo de privatização do sistema público de ensino goiano.

Enquadrou-se, segundo a perspectiva da administração, a ideia de submeter todos os candidatos a diretores de escola da Rede Estadual de Ensino a um teste de conhecimentos gerenciais (empreendedorismo, inovação, controle, qualidade etc.) e da normativa que impede a candidatura dos "reprovados" e que submete toda a escola à racionalidade do controle expresso no Índice de Gestão.

Será considerado o Índice de Gestão, uma ferramenta de avaliação do cumprimento de tarefas pelo Grupo Gestor nas escolas. Será composto pelo cumprimento do calendário escolar, inserção diária dos dados da escola no Sistema de Gestão Escolar do Estado de Goiás (SIGE) e manutenção de canal de comunicação com a Secretaria da Educação. Ao Grupo Gestor caberá dar unidade ao trabalho em equipe. Ele será o responsável por observar o cumprimento do calendário, inserir os dados de frequência diária dos alunos no SIGE, as notas, a frequência do professor e acessar diariamente os canais de comunicação interna da Secretaria da Educação e verificar diariamente os e-mails. Esses critérios serão acompanhados em conjunto: para efeito de bonificação, eles farão parte de um índice de gestão, que determinará o percentual do bônus a que o grupo gestor terá direito. (GOIÁS, 2013, [s.p.]) 
Para efeitos de controle do controle no interior de cada escola, criou-se um agente novo no processo, o tutor pedagógico:

Todo tutor pedagógico deverá acompanhar, no quadro de frequência afixado em local visível no Núcleo Pedagógico da subsecretaria, o lançamento diário dos acompanhamentos. Caberá aos tutores pedagógicos verificar se as informações lançadas no sistema (SIIGNET) pelo Diretor do Núcleo Pedagógico da subsecretaria estão de acordo com os dados informados diariamente no quadro de frequência. (GOIÁS, 2013, [s.p.])

Reduziu-se o fazer docente a não trabalho ou à recusa da práxis. Ou seja, transformou-se a atividade do professor em um conjunto de ações burocráticas limitadas pela execução de rotinas, pela produção de relatórios padrões e subordinadas à ditadura do bônus.

\begin{abstract}
A Secretaria da Educação fornecerá um modelo deste plano. O professor regente e a equipe pedagógica, juntos, vão preenchê-lo com dados referentes à expectativa de aprendizagem, ao conteúdo e às metodologias a serem utilizadas em cada aula. Esse planejamento será quinzenal e auxiliará na estruturação do trabalho pedagógico da escola. Para efeito de bonificação, uma aula será considerada efetivamente ministrada apenas se o seu planejamento tiver sido entregue. (GOIÁS, 2013, [s.p.])
\end{abstract}

Institucionalizou-se a fragmentação do conhecimento ao sugerir que a escola deve isolar seu fazer pedagógico em séries, que o patrimônio cultural da humanidade seja convertido em unidades isoladas sob a forma de disciplinas e que estas sejam transformadas em conteúdos ministráveis segundo as exigências (expectativa de aprendizagem, eixos temáticos etc.) predeterminadas burocraticamente em ambientes totalmente surdos à comunicação que se estabelece na particularidade de cada unidade de ensino. Independente do Projeto Político Pedagógico da Escola, o Currículo de Referência determina:

1. ${ }^{\circ}$ ANO / ENSINO FUNDAMENTAL:

1. ${ }^{\circ}$ BIMESTRE:

EXPECTATIVAS DE APRENDIZAGEM

- Comunicar-se com clareza fazendo-se entender. • Respeitar os diferentes modos de falar de outras pessoas. - Expressar seus desejos, vontades, necessidades e sentimentos nas diversas situações de interação presentes no cotidiano. • Representar a fala de personagens do conto de fada ouvido. • Ouvir com atenção.

- Comunicar-se por meio de gestos, expressões e movimentos corporais.

EIXOS TEMÁTICOS: Prática de Oralidade

CONTEÚDOS: • Gravuras. • Embalagens. • Contos de fadas.

(GOIÁs, 2012, [s.p.]) 
Ainda que a ideia de determinação tente ser amenizada pela perspectiva de referência e consultas nos casos de incerteza, o que se tem, de fato, é a conversão do ensino do conteúdo em fim do processo e a transformação da orientação em determinação sujeita a controle total, obrigatoriedade, camisa de força, entrave para que a ação docente possa se efetivar como trabalho. É exatamente o que evidencia a cartilha do Programa ao estabelecer as mediações que devem orientar a relação entre o chamado grupo gestor e os professores das unidades de ensino.

Diretor, Vice-Diretor e Secretário Geral deverão se organizar para: a. Afixar o quadro semanal de aulas na entrada de cada sala de aula, com os horários das disciplinas e os nomes dos respectivos professores; [...] c. Lançar à tinta, diariamente, o número de aulas programadas/ministradas de cada professor [...] d. Verificar com os coordenadores pedagógicos, a cada 2 semanas, se os planos de aula foram entregues no prazo (até $1 .^{\circ}$ dia útil do período de 2 semanas em que as aulas planejadas vão ocorrer), e lançar informação tanto no quadro de frequência afixado no mural (à tinta) quanto no SIGE; O prazo para esse lançamento no sistema (SIGE) se encerrará sempre às 23h59min [...]. (GOIÁS, 2013, [s.p.])

Portanto, está explícito o que se pretende dizer de fato quando se afirma que "há uma urgência em superar uma proposta curricular fragmentada e despertar para a busca da qualidade da aprendizagem em nosso estado" (GOIÁS, 2013, [s.p.]). Para que não pairem dúvidas acerca do que se deva entender por princípio de qualidade, é o próprio documento que faz o arremate:

Além disso, a Secretaria de Estado da Educação realizará auditoria permanente
para conferência dos dados. Caso seja constatada fraude em uma unidade
educacional, todos os professores regentes, coordenadores pedagógicos e
integrantes do grupo gestor dessa unidade perderão o direito à parcela semestral
do bônus. (GOIÁS, 2013, [s.p.])

A cartilha "Programa Reconhecer, o Mérito é Seu" (GOIÁS, 2013, [s.p.]) apresenta o Currículo de Referência como “[...] instrumento pedagógico para orientar, de forma clara e objetiva, aspectos que não podem se ausentar no processo ensino-aprendizagem em cada disciplina, ano de escolaridade e bimestre". Contudo, o que se tem de fato é a instituição da obrigatoriedade de um fazer docente centrado na aula em sua perspectiva mais limitada, intervalo de tempo altamente regulado, no qual se deve transmitir, segundo a racionalidade seriada, um conjunto de informações sem conexão histórica e destituídas de qualquer sentido de universalidade ou transcendência.

Contraditoriamente, o mesmo documento que apresenta o "Currículo de Referência" como orientação, atrela a entrega de 
planos de aula, segundo as determinações de forma e conteúdo nele expressos, como condição para o recebimento de bônus por parte de professores, coordenadores e corpo dirigente das escolas.

O próprio SIGE dispõe de programas que vão indicar se houve ou não a inserção diária dos dados pelas escolas e se os e-mails e outras comunicações foram acessadas a cada dia. Da mesma forma que o trabalho dos professores, a atuação do Grupo Gestor para a bonificação do Reconhecer será permanentemente avaliada por equipes das Subsecretarias Regionais de Educação e do Núcleo de Orientação Pedagógica da SEDUCE. (GOIÁS, 2013, [s.p.])

Subverteu-se o espírito de cooperação, fundamental à organização do trabalho pedagógico, ao promover como princípio uma atmosfera de conflito contínuo em virtude da vigilância total advinda da conversão de todos os profissionais em polícias de seus pares, ou seja, de si próprios. Como a lógica da ideologia do mérito não consegue e não pode assegurar "premiação" a todos, é necessário criar um sistema de disputa interna e de controle extremo no interior das instituições de ensino ${ }^{2}$.

Por outro lado, toda essa articulação possibilitou a transferência direta de recursos públicos para grupos privados diversos. Cita-se apenas como exemplo os contratos que desde 2011 vêm sendo celebrados com empresas de consultoria como a própria Bain\&Company, com gráficas particulares especializadas em produção de materiais didáticos complementares e mesmo com a grande indústria de eletroeletrônicos, por meio de seus representantes, donos de cadeiras cativas nos grandes fóruns mundiais em defesa do sistema de acumulação de capital.

O projeto One Laptop per Children (OLPC) foi apresentado ao governo brasileiro, em janeiro de 2005, no Fórum Econômico Mundial em Davos - Suíça. Ainda no mesmo ano, Nicholas Negroponte, Seymour Papert e Mary Lou Jepsen vieram ao Brasil especialmente para conversar com o presidente e detalhar a proposta de implantação do programa. (ECHALAR, 2015, p. 53)

A Contrarreforma da Educação Básica goiana, como em praticamente todos os Estados que vêm seguindo as diretrizes da organização "Todos pela Educação", tem como característica importante a compra de pacotes do tipo conteúdos/técnicas de ensino-aprendizagem. Só o "Pacto Pela Educação" em Goiás, por exemplo, vem movimentando milhões com a contratação do Programa do Instituto de Corresponsabilidade Pela Educação do Estado de Pernambuco (ICE - Brasil), com a aquisição de cadernos didáticos como o Roteiro de Didática Aplicada - RODA e a compra de laptops compatíveis com os modelos sugeridos pelo projeto One Laptopper Children, o mesmo que ressoa explicitamente nas estratégias do Plano Decenal de Educação aprovado em 2015/2025. 
7.15) universalizar, até o quinto ano de vigência deste PNE, o acesso à rede mundial de computadores em banda larga de alta velocidade e triplicar, até o final da década, a relação computador/aluno(a) nas escolas da rede pública de educação básica, promovendo a utilização pedagógica das tecnologias da informação e da comunicação. (BRASIL, 2014, [s.p.])

Assim sendo, a partir do caso goiano, pode-se afirmar que se está diante de uma grande ação de reordenamento fiscal, travestida de reforma político-pedagógica. É o que anuncia todo o movimento que marca a segunda fase da implantação do "Pacto". No apagar das luzes de 2014, sob o argumento da necessidade de racionalização do aparelho estatal, a Secretaria Estadual de Educação (SEDUCE/GO), por força da Lei n. ${ }^{\circ}$ 18.687, de 3 de dezembro de 2014, foi transformada em uma grande secretaria de Estado, passando a centralizar, além dos recursos da educação, as verbas destinadas à cultura, ao esporte e ao lazer (SEDUCE/GO). Para o gerenciamento da superestrutura orçamentária, foi escolhida ninguém menos que a sra. Raquel Teixeira, membro da Comissão Técnica da Organização "Todos Pela Educação", ex-deputada federal, ex-presidente da Fundação Jaime Câmara e agente diretamente ligada ao grupo econômico que desde a fundação de Goiânia vem se empenhando na hipertrofia do partido de classe burguesa no Estado. Portanto, uma coluna (intelectual orgânica) de ponta do bloco histórico que historicamente faz da sociedade política goiana guarida de seus interesses.

A partir dessa reestruturação, o governo do Estado de Goiás criou as condições materiais necessárias para a privatização do sistema de ensino via Organizações Sociais - OSs. No final do ano de 2015, ainda sob a forma de balão de ensaio, o projeto começou a ser defendido nos principais veículos de comunicação social, criando, assim, uma atmosfera favorável para sua aprovação. Dessa forma, a despeito dos protestos do meio acadêmico, de parte do quadro de professores e das ocupações das escolas por estudantes da rede estadual, o projeto foi aprovado em questão de semanas e a SEDUCE divulgou o Chamamento Público n. ${ }^{\circ}$ 001/2016, para contratação das ditas Organizações Sociais. Nem mesmo os questionamentos do Ministério Público Federal e Estadual foram suficientes para demover a Secretaria da ideia de transferir para empresários toda a administração de unidades de ensino do Estado, incluindo no pacote o direito de contratar professores via CLT e a transferência direta dos recursos destinados ao custeio e à manutenção para os cofres privados ${ }^{3}$.

O relatado acima é uma prova clara de que a discussão da qualidade e da preservação do bem coletivo não está em questão, mas sim o interesse do ente público em financiar a reprodução do sistema 
de acumulação do capital, por meio da combinação de terceirização e redução dos investimentos em educação. Tanto é verdade que mesmo com a Secretaria de Educação, Cultura e Esporte gastando com cada aluno R \$338,90 (conforme Stecca (2016)), o edital que convoca as Organizações Sociais define que o custo por aluno deverá variar em torno de $R \$ 250,00$ a 350,00 reais, e que um dos critérios para a escolha das Organizações Sociais será a capacidade de aproximação do menor valor. Dando prioridade a esse tipo de questão, a mesma Chamada Pública não enfrenta o debate do processo pedagógico, do papel do professor e da formação integral do aluno. Ou seja, reduz-se a questão da qualidade da educação à ditadura do econômico e dos resultados obtidos pelos testes padronizados. Não era a discussão da qualidade da escola pública que estava em questão na pauta da SEDUCE, mas, sim, a reprodução da tese da eficiência, pela qual supostamente se faz "mais com menos".

Nesse sentido, pode-se perceber que, no campo das políticas educacionais em Goiás, os debates e ações giram em torno da privatização via concessão, da entrega das escolas para Polícia Militar, de um metodologismo centrado no superdimensionamento das técnicas de ensino, na aposta em aprendizagem individualizada e na patologização do fracasso escolar.

Tomando de empréstimo a análise de Singer (2012), o caso em questão corresponde a um movimento que engrossa o conjunto de mudanças das últimas duas décadas, que devem ser entendidas como materialização de reformismo fraco, que reproduz e faz avançar as contradições brasileiras. São resultados do pragmatismo "político", da governabilidade a qualquer preço e do Estado de exceção que se instaurou entre nós, sob a forma de "reforma gradual e pacto conservador". A dificuldade neste momento é que esse processo se nutre da produção da cultura do ódio, do transbordar do caldo fascista que historicamente permeia as práticas sociais brasileiras e da explosão de manifestações que de forma assustadora têm revelado a desagregação social e a intolerância materializadas não só nas ruas, mas também na mídia e nas redes sociais. São sintomas de um tempo no qual a ausência da política e dos movimentos sociais passou a rejeitar o sistema político e, por assim dizer, isolá-lo da sociedade e aceitá-lo apenas a partir de ativismos judiciais - são os tempos sombrios da Contrarreforma.

\section{SEM A PRETENSÃO DE ENCERRAR: O DILEMA DE TENTAR CONCLUIR}

Ainda que toda a inspiração panfletária dos arautos do juízo final tenha sido pródiga em produzir odes em louvor ao consenso universal 
da sociedade civil virtuosa, ao culto do reino do fim dos conflitos de toda a natureza, especialmente de classe, as primeiras décadas do século XXI não têm feito cerimônia em provar que o sujeito político ainda não se deu por vencido. Ou seja, continua em movimento e permanece vigilante em sua missão de produzir, na incontrolável dinâmica do real, as condições para se projetar como humanidade.

A base material dominante cria as ideias dominantes, mas, contraditoriamente, também fertiliza as condições para que letras e melodia se articulem em coros dissonantes, ainda que marginais. A ação de classe que fertiliza o nascimento de organizações como o "Todos Pela Educação", que, por sua vez, cria as condições concretas para a aprovação de projetos de reestruturação do Sistema Público de Ensino em "parcerias" com as secretarias estaduais de educação, ou mesmo a estranha redefinição dos marcos legais do "Plano Nacional de Educação", ao mesmo tempo em que sugere uma espécie de consenso em torno dos princípios de classe burguesa, fomenta, entre os movimentos sociais, protestos, manifestações e ocupações de escolas, aquilo que Löwi (2014) define como centelha criativa.

O conluio dos representantes nacionais dos grandes grupos econômicos locais, ávidos por converter a experiência formativa brasileira em instrução mediada pelo princípio da submissão do trabalho ao capital, fomenta entre os estudantes o sentimento criativo, a contraordem e a insubordinação, consolidando uma ação coletiva de afirmação dos dois grandes princípios sociais e políticos: “[...] primeiro, o princípio republicano da educação - a educação é pública; segundo, o princípio democrático da educação - a educação é um direito" (CHAUÍ, 2016, p. 16).

Nesse sentido, pode-se afirmar que a contradição e o conflito continuam vivos e, a menos que produza um novo projeto societal, baseado em novas relações de produção, tende a permanecer. A despeito dos consensos de um tempo histórico que produzem organizações como a "Todos Pela Educação" e as Organizações Sociais em Goiás, a realidade vem confirmando que é a dinâmica mágica da produção da mercadoria que produz as ilusões, as visões parciais e, por assim dizer, toda a sorte de desentendimentos, inclusive o conflito fundamental. Não é a negação idealística das classes que elimina o conflito. Ele é inerente ao sistema produtivo, que guarda como segredo a divisão dos homens entre proprietários dos meios de produção e executores de tarefas.

As ocupações das escolas públicas por alunos e professores contrários às parcerias de gestão entre governo e Organizações Sociais, processo em curso em Goiás e nascido como produto de mais um capítulo 
do conflito entre capital e trabalho, é a confirmação e a atualização dos sujeitos políticos. Deve ser compreendido como um potencial inovador, raio em manhã de sol, que, por meio da insurgência cidadã contra a ideia de sociedade civil "virtuosa" e da transição negociada que formatou o consenso administrado por cooptação desde meados dos anos 1985, vem revelando a contradição da democracia brasileira e tornando patente o fosso entre o sistema político e a sociedade.

Sendo assim, mesmo no calor dos fatos ainda por se desenrolar, é importante esboçar tendências e alguns achados que o atual momento da luta social pelo direito à escola já anunciam. O debate sobre o papel das Organizações Sociais na educação talvez seja aquele de maior relevância na política de privatização dos bens públicos nas últimas décadas no Brasil. Refletir sobre esse fenômeno social é importante não só pelos impactos que produz em matrizes pedagógicas, mas fundamentalmente, porque se trata de um particular histórico que expressa a materialização de importantes tendências silenciosas de privatização do público, nascidas nos anos 1990 e, aparentemente, mesmo que do ponto de vista hegemônico, irreversíveis.

\section{REFERÊNCIAS}

AUGUSTO, C. A Nova Educação em Goiás. Site da Rádio Fonte FM. 2012. Disponível em: < http://fontefm.redefonte.com/2012/01/18/artigo-do-apostolo-cesar-augusto-nojornal-diario-da-manha-a-nova-educacao-em-goias/>. Acesso em: 16 abr. 2016.

BAIN \& COMPANY BRASIL. Quem Somos. Site da instituição. [2016?]. Disponível em: <http://www.bain.com/offices/saopaulo/pt/who-we-are/index.aspx>. Acesso em: 16 out. 2016.

BRASIL. Ministério de Educação e Cultura. LDB-Lei n. ${ }^{\circ}$ 9.394/1996, de 20 de dezembro de 1996. Estabelece as diretrizes e bases da Educação Nacional. Brasília: MEC, 1996. Disponível em: < http://portal.mec.gov.br/seesp/arquivos/pdf/lei9394_ldbn1.pdf>. Acesso em: 16 out. 2016.

BRASIL. Plano Nacional de Educação (PNE). Plano Nacional de Educação 2014-2024 [recurso eletrônico]: Lei n. ${ }^{\circ}$ 13.005, de 25 de junho de 2014, que aprova o Plano Nacional de Educação (PNE) e dá outras providências. Brasília: Câmara dos Deputados, Edições Câmara, 2014. 86 p. (Série Legislação, n. 125)

BRASIL. Ministério de Educação e Cultura. Decreto n. ${ }^{\circ}$ 6.094/2007. Dispõe sobre a implementação do Plano de Metas Compromisso Todos Pela Educação. Brasília: Presidência da República, 2007. Disponível em: < http://www.planalto.gov.br/ccivil_03/_ato20072010/2007/decreto/d6094.htm>. Acesso em: 16 out. 2016.

CHAUÍ, M. Sociedade Brasileira: violência e autoritarismo por todos os lados. Revista Cult, Edição 209, p. 8-17, 2016. 
CRUZ, J. A. Organizações Não-Governamentais, Reforma do Estado e Política no Brasil: um estudo com base na realidade de Goiás. 2002. 218 f. Tese (Doutorado em Educação) - Universidade Estadual de Campinas, Campinas, 2005.

ECHALAR, A. D. L. F. Formação Docente para a Inclusão Digital via Ambiente Escolar: o PROUCA em questão. 2015. 148 f. Tese (Doutorado em Educação) - Pontifícia Universidade Católica de Goiás, Goiânia, 2015.

FERREIRA, W. Mudanças, de forma geral, provocam resistência. Jornal O Popular, Goiânia, Edição 77/22524, Seção Agenda, 2015.

GOIÁS. Secretaria Estadual de Educação. Lei n. ${ }^{\circ}$ 17.402/2011, de 6 de setembro de 2011, que institui o Bônus de Estímulo à Regência. Goiânia: Governo do Estado de Goiás, 2011. Disponível em: <http://www.gabinetecivil.goias.gov.br/leis_ordinarias/2011/ lei_17402.htm>. Acesso em: 16 out. 2016.

GOIÁS. Secretaria Estadual de Educação. Currículo de Referência da Rede Estadual de Educação de Goiás. 2013. Goiânia: Governo do Estado de Goiás, 2012. Disponível em: <http://www.seduc.go.gov.br/imprensa/documentos/arquivos/Curr $\% \mathrm{C} 3 \%$ ADculo $\% 20$ Refer $\%$ C3\%AAncia/Curr\%C3\%ADculo\%20Refer\%C3\%AAncia\%20da $\% 20$ Rede $\% 20$ Estadual $\% 20$ de $\% 20$ Educa $\%$ C3 $\%$ A $7 \%$ C3\%A3o $\% 20$ de $\% 20$ Goi $\%$ C3\%A1s!.pdf > . Acesso em: 16 out. 2016

GOIÁS. Secretaria Estadual de Educação. Programa Reconhecer, Educação o Mérito é Seu. Goiânia: Governo do Estado de Goiás, 2013. Disponível em: < http:/ /www.see.go.gov. br/documentos/cartilha\%202012.pdf>. Acesso em: 16 out. 2016.

GRAMSCI, A.Cadernos do Cárcere. Rio de Janeiro: Civilização Brasileira, v. 6, 2002.

LIMA, G. Educação mobiliza Agenda Goiás em Catalão. Jornal O Popular, Edição 77/22524, Seção Agenda, 2015.

LÖWY, M. A Centelha se Acende na Ação: a auto-educação dos trabalhadores no pensamento de Rosa Luxemburgo. Revista Educação e Filosofia, v. 28, n. 55, p. 27-38, 2014.

MONTENEGRO, I. Educação mobiliza Agenda Goiás em Catalão. Jornal O Popular, Goiânia, Edição 77/22524, Seção Agenda, 2015.

TODOS PELA EDUCAÇÃO. Métodos Inovadores de Ensino. Site da organização. [2016?]. Disponível em: <http://www.todospelaeducacao.org.br/projetos/todos-osprojetos/130/metodos-inovadores/>. Acesso em: 15 abr. 2016.

PEIXOTO, T. Educação Mobiliza Agenda Goiás em Catalão. Jornal O Popular, Goiânia, Edição 77/22524, Seção Agenda, 2015.

OLIVEIRA, F.; RIZEK, C. S. (org.). A Era da Indeterminação. São Paulo: Boitempo, 2007.

PEREIRA, B. A Reforma do Estado dos Anos 90: lógica e mecanismos de controle. Revista Lua Nova, n. 45, p. 49-95, 1998.

RAVITCH, D. Vida e Morte do Grande Sistema Escolar Americano: como os testes padronizados e o modelo de mercado ameaçam a educação. Porto Alegre: Sulina, 2011.

SINGER, A. Os Sentidos do Lulismo: reforma gradual e pacto conservador. São Paulo: Companhia das Letras, 2012. 
STECCA, K. Gestão das Escolas Públicas em Perspectivas. Jornal UFG, ano X, n. 77, p. 10-11, 2016.

VIANNA, Luiz Werneck. A Revolução Passiva: iberismo e americanismo no Brasil. Rio de Janeiro: Revan, 1997.

\section{NOTAS}

${ }^{1}$ Gramsci tomou como referência histórica a Reforma Protestante para elaborar o conceito de Reforma Passiva, e a Contrarreforma Católica para a Contrarreforma Burguesa, em meados do século XX.

${ }^{2}$ O Governo do Estado de São Paulo, que desde 2008 vem desenvolvendo suas políticas educacionais a partir da ideologia da meritocracia, vem demonstrando que políticas dessa natureza, em médio prazo, negam inclusive a lógica de reprodução do capital. Isso porque o processo que cria a norma de comportamento também possibilita os mecanismos de subversão (conversão da organização do fazer docente em treinamento, transformação da avaliação em testes internos de obtenção de médias etc.) No limite, isso acaba por promover uma curva ascendente nos índices e, por consequência, a necessidade de destinação cada vez maior de recursos para o custeio das premiações. Como a sanha acumulativa do capital impede a crescente conversão de recursos públicos para o custeio do Estado social, a alternativa acaba sendo o calote ou a revelação da ilusão, conforme matéria do sítio G1 São Paulo, em 9/3/2016: “O governo estadual de São Paulo cancelou o pagamento de bônus por mérito aos professores da rede. É a primeira vez, desde 2008, quando o bônus foi criado, que deixará de ser pago".

${ }^{3} \mathrm{O}$ chamamento para OSs interessados em administrar as escolas do Estado, em uma primeira fase incluiu 23 escolas, chegando a 200 até o final do ano de 2016. Assim, Goiás, que até a data da chamada pública não possuía sequer uma única Organização Social especializada em administração de escolas, após a publicação, passou a contar com nada menos que 21 OSs, criadas às pressas e, portanto, sem a menor estrutura para desempenhar a tarefa, conforme reconheceu a própria Secretaria de Educação. Acuada pelos movimentos sociais e pelo questionamento do Ministério Público, a Secretaria Estadual de Educação foi obrigada a recusar temporariamente todas as propostas apresentadas, alegando que nenhuma das Organizações possuía as condições mínimas exigidas.

Submetido: $10 / 02 / 2016$

Aprovado: 15/03/2017

Contato:

Álcio Crisóstomo Magalhães

Escola Superior de Educação Física e

Fisioterapia do Estado de Goiás

Av. Anhanguera, n. 3228 - Setor Leste Universitário

Goiânia $\mid \mathrm{GO}$ | Brasil

CEP 74.643-010. 